\title{
ANTIOXIDANT ABILITIES COMPARISON OF LIGNINS WITH THEIR HYDROTHERMAL LIQUEFACTION PRODUCTS
}

\author{
Shimin Kang, Biao Li, Jie Chang,* and Juan Fan \\ Black liquor alkaline lignin and magnesium lignosulfonate were liquefied \\ at $320{ }^{\circ} \mathrm{C}$. The antioxidant abilities of the liquefaction products were \\ compared with the raw materials. Results showed that the total phenol \\ content and unit antioxidant power of both alkaline lignin liquefaction \\ products (ALLP) and magnesium lignosulfonate liquefaction products \\ (MLLP) were improved, and ALLP had a larger increase than MLLP. The \\ influence of reaction time and temperature on oil yield, total phenol \\ content, and antioxidant power of ALLP was evaluated. The total phenol \\ content was found to have certain relationships with the antioxidant \\ abilities. These results explore a new approach for further studies and \\ applications of liquid antioxidant from lignins.
}

Keywords: Alkaline lignin; Lignosulfonate; Antioxidant; Hydrothermal; Liquefaction

Contact information: Pulp \& Paper Engineering State Key Laboratory, School of Chemistry and Chemical Engineering, South China University of Technology, Guangzhou, Guangdong 510640, China; *Corresponding author: changjie@scut.edu.cn

\section{INTRODUCTION}

Black liquor alkaline lignin and lignosulfonates are common components of pulp and paper wastewaters, and they are hazardous environmental pollution sources. Lignins are polyphenolic compounds that contain phenolic groups, which possess antioxidant characteristics. Antioxidant effects of lignins have been reported in rubber, plastic, thermomechanical pulp, medicines, and dietary products (Xin and Saka 2009). Recent studies have revealed the efficiency, as antioxidants in different composite materials, of lignins isolated from wood by different methods of delignification, including alkaline pulping and some lignin-related monomeric and dimeric compounds (Dobeleet al. 2009). Bhat et al. (2009) have explored the antioxidant potential of lignin isolated from black liquor of oil palm waste, and they found that the extracted lignin exhibited rich antioxidant/free radical scavenging potential. Ugartondo et al. (2008) found that lingosulfonates have a high antioxidant capacity over a range of concentrations, and the suitability of these lignosulfonates was assessed for new commercial applications in cosmetics and pharmaceuticals.

These reports suggest that lignins from pulp and paper wastewater can be a source for antioxidant production. However, good solubility and mobility are important factors affecting the stabilisation properties of antioxidants. Lignins are polar polymers, and thus exhibit a very poor solubility in some apolar media, and lignosulfonates are insoluble in common organic solvents. These factors may limit their antioxidant reactivity and then limit their applications. Also, the high molecular weight and polydispersity of lignins are factors that decrease radical scavenging activity (Pan et al. 2006). Lignins in 
hydrothermal conditions can be degraded to low molecular weight products, mainly phenolic compounds. Such phenolic compounds possess antioxidant properties and better solubility in most apolar or polar media. However, almost all the research in hydrothermal conditions has focused on conversion of lignins into value-added products such as bio-oil or energy gas. By contrast, the present work investigates and compares the antioxidant abilities of alkaline lignin and magnesium lignosulfonate with that of their hydrothermal liquefaction products.

\section{EXPERIMENTAL}

\section{Materials}

Alkaline lignin was obtained from Wuhan East China Chemical Co., Ltd., China. Magnesium lignosulfonate was obtained from The Jiangmen Sugarcane Chemical Factory (Group) Co., Ltd., China. 1,1-diphenyl-2-picrylhydrazyl (DPPH) radicals (97\%) and 2,4,6-tri-2-pyridyl-s-triazin (TPTZ) were obtained from Tokyo Chemical Industry Co., Ltd., Japan. Folin-Ciocalteu phenol reagent was obtained from Guangzhou Qiyun Biotechnology Co., Ltd., China.

\section{Liquefaction Method}

Hydrothermal liquefaction experiments were conducted in a $250 \mathrm{~mL}$ stainless steel 316 autoclave with $1.5 \mathrm{~kW}$ heating power. The autoclave was loaded with $5.0 \mathrm{~g}$ alkaline lignin (or magnesium lignosulfonate) and $60 \mathrm{~mL}$ water. Then the reactor was purged 5 times with nitrogen to remove the inside air. After that the autoclave was under an initial nitrogen pressure of $2.0 \mathrm{MPa}$. The reactants were stirred at $100 \mathrm{rpm}$. When the temperature reached the setting values, the reaction time was recorded as zero, and thereafter the reaction time was recorded. The liquid and solid products were separated after reaction. Oil 1 was the extracted oil phase from liquid products with $250 \mathrm{~mL} \mathrm{CH}_{2} \mathrm{Cl}_{2}$ used 5 times, and oil 2 was the extracted liquid phase of solid products obtained via soxhlet extractor with $60 \mathrm{~mL} \mathrm{CH} \mathrm{Cl}_{2}$. Then oil 1 and oil 2 were mixed, and the mixture was distilled at $45{ }^{\circ} \mathrm{C}$ to exclude $\mathrm{CH}_{2} \mathrm{Cl}_{2}$. Then the remaining material consisted of the alkaline lignin liquefaction products (ALLP) (or magnesium lignosulfonate liquefaction products (MLLP)). The extracted solid products (residues) were dried and weighed. For the subsequent total phenol content and antioxidant power tests, the ALLP, MLLP, alkaline lignin, and lignosulfonate with the same concentrations, $0.53 \mathrm{~g} / \mathrm{L}$ were prepared.

\section{Total Phenol Content Assay}

The Folin-Ciocalteau method was used to test total phenol content. Results were expressed in g gallic acid (GA)/100g. The absorbance was measured at $760 \mathrm{~nm}$.

\section{DPPH Method}

The antiradical activities of various antioxidants were determined using 1,1diphenyl-2-picrylhydrazyl (DPPH) radical (Brand-Williams et al. 1995). $0.2 \mathrm{~mL}$ samples $(0.53 \mathrm{~g} / \mathrm{L})$ were mixed with DPPH radical ethanol solutions, and then kept in the shade for $30 \mathrm{~min}$, the absorbance at $517 \mathrm{~nm}$ was recorded $A_{i}$. As the method of measuring $A_{i}$, the

Kang et al. (2011). "Lignins with their liquefaction products," BioResources 6(1), 243-252. 244 
absorbance of the solution containing all the reagent beside sample was recorded as $A_{0}$, The DPPH radicals scavenging percentages were calculated as $\left[\left(A_{0^{-}} A_{i}\right) / A_{0}\right]$.

\section{Ferric Reducing Antioxidant Power (FRAP )}

The FRAP method was used to test antioxidant power (Castro et al. 2008), with absorbance tested at $593 \mathrm{~nm}$. An aqueous solution of known $\mathrm{Fe}^{2+}$ conc. (in range 0.05 to $1.2 \mathrm{mmol} / \mathrm{L}$ ) was used for calibration. $0.2 \mathrm{~mL}$ samples were mixed with $3 \mathrm{~mL}$ water and 2 mL FRAP reagent. Greater reduction of $\mathrm{Fe}^{3+}$ to $\mathrm{Fe}^{2+}$ means better antioxidant power.

\section{Fourier Transform Infrared Spectroscopy (FT-IR) Analysis}

The raw material and their liquefaction products were analyzed with a Vector33 FT-IR spectrophotometer (Bruker Co., Ltd., Germany).

\section{GC-MS Analysis}

The composition of ALLP produced at $320{ }^{\circ} \mathrm{C}, 30$ min were analyzed using a Shimadzu QP 2010 Plus equipped with Rxi-5ms column $\left(30 \mathrm{~m}^{*} 0.25 \mathrm{~mm} * 0.25 \mu \mathrm{m}\right)$. The temperature of the injector was set at $280{ }^{\circ} \mathrm{C}$. Temperature program: $40{ }^{\circ} \mathrm{C}$ (hold $2 \mathrm{~min}$ ) $\rightarrow 180{ }^{\circ} \mathrm{C}\left(3{ }^{\circ} \mathrm{C} / \mathrm{min}\right) \rightarrow 280{ }^{\circ} \mathrm{C}\left(20{ }^{\circ} \mathrm{C} / \mathrm{min}\right.$, hold $\left.5 \mathrm{~min}\right)$. The compounds in the ALLP were identified by means of the NIST08 and NIST08s mass spectral data libraries.

\section{RESULTS AND DISCUSSION}

The oil and residue yields are shown in Fig. 1. Both the oil and residue yields of alkaline lignin were less than that of magnesium lignosulfonate, which may be explained by the difference in composition. The alkali in alkaline lignin is an effective catalyst, which may inhibit char formation (possibly through decomposition of HCHO) and promote gas formation (through water gas shift reaction) (Watanabe et al. 2003). The char formation and alkaline effects mechanism are shown in Fig. 2 (Watanabe et al. 2003; Osada et al. 2006). In the alkaline catalyst system, lignins are easier to decompose and more gases are produced. On the other hand, the alkali can be removed from the liquefaction products due to its water solubility during the products separation.
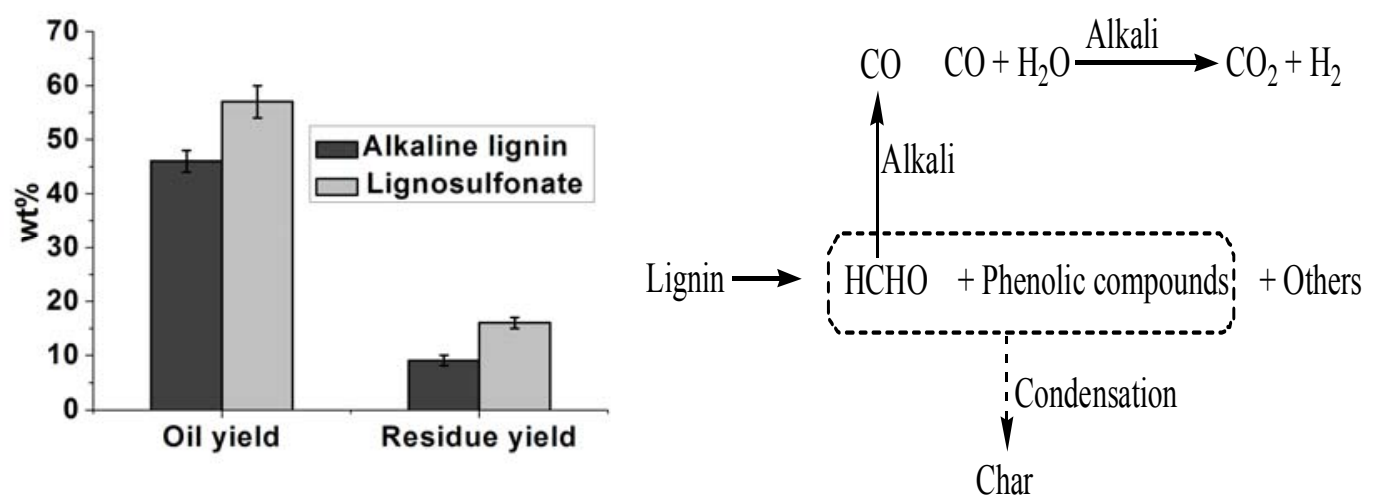

Fig. 1. (left) Oil and residue yield after liquefaction at $320^{\circ} \mathrm{C}, 30 \mathrm{~min}$

Fig. 2. (right) Char formation and alkaline effects mechanism 
The alkaline lignin and ALLP were characterized by FTIR in the region of 4000 to $500 \mathrm{~cm}^{-1}$, as shown in Fig. 3A. Both spectra show most of the characteristic bands of lignin, including 1510 and $1600 \mathrm{~cm}^{-1}$ (aromatic ring vibrations) and $1460 \mathrm{~cm}^{-1}(\mathrm{CH}$ deformation and aromatic ring vibrations). The absorbance peak of $\mathrm{O}-\mathrm{H}$ stretching vibrations between 3300 and $3600 \mathrm{~cm}^{-1}$ are due to alcoholic or phenolic components. The peaks around 1260 and $1220 \mathrm{~cm}^{-1}$ indicate the possible presence of phenols and esters, showing the $\mathrm{O}-\mathrm{H}$ deformation vibration and $\mathrm{C}=\mathrm{O}$ stretching. The peaks around 690,740 , and $810 \mathrm{~cm}^{-1}$ indicated the presence of monosubstituted and polysubstituted aromatic groups. The FTIR spectra change of MLLP with lignosulfonate is similar to that of ALLP with alkaline lignin, as shown in Fig. $3 \mathrm{~B}$.
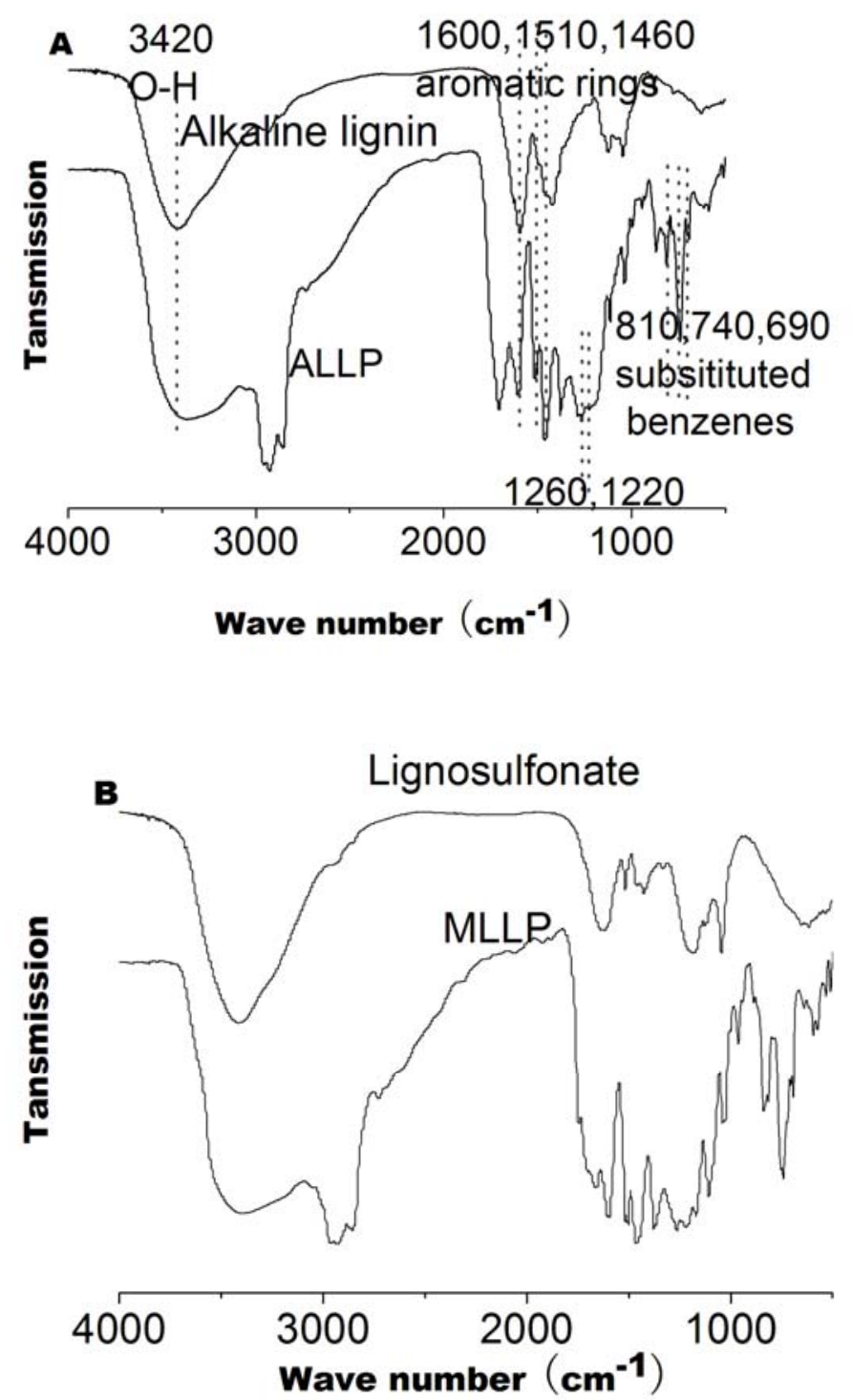

Fig. 3. FT-IR spectra: (A) alkaline lignin with ALLP; (B) lignosulfonate with MLLP. The ALLP and MLLP were obtained at $320^{\circ} \mathrm{C}, 30 \mathrm{~min}$ 
The FTIR spectra indicate that alkaline lignin was decomposed to some low molecular weight phenolic compounds. This finding was confirmed by GC-MS. As shown in Fig. 4 and Table 1, phenols were the main products in ALLP. However, the decomposition of alkaline lignin and lignosulfonate hardly changed the distribution of the functional groups, which means that the liquefaction products have the potential to possess antioxidant properties. Moreover, it has been reported that low molecular weight lignin showed high antioxidant activity (Pan et al. 2006).

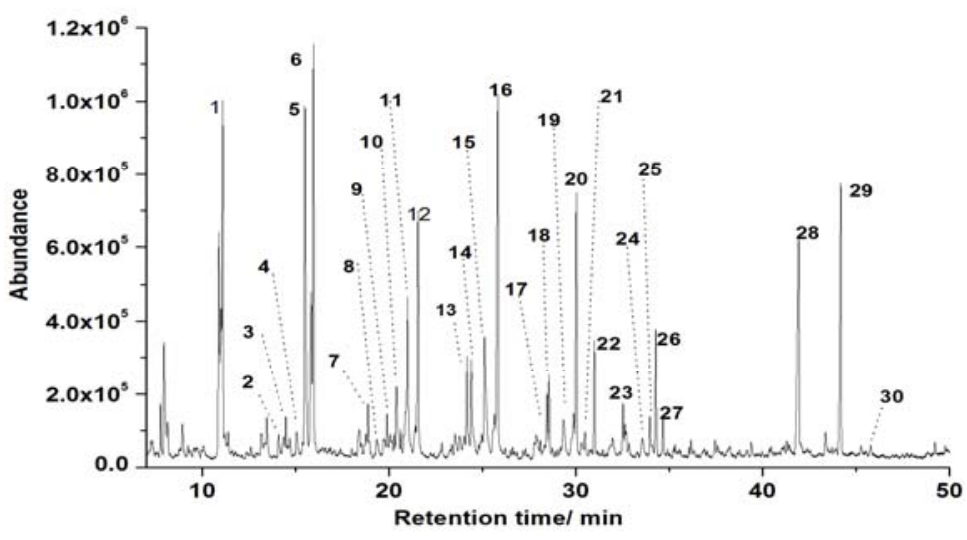

Fig. 4. GC-MS analysis of ALLP obtained at $320^{\circ} \mathrm{C}, 30 \mathrm{~min}$.

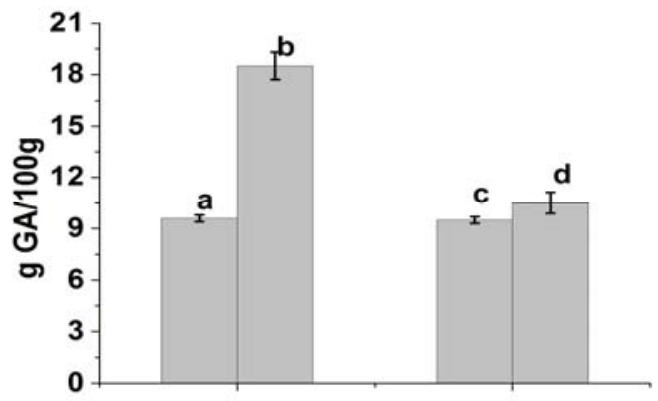

Fig. 5. Total phenol content, a: alkaline lignin; b: ALLP; $\mathbf{c}$ : lignosulfonate; and d: MLLP. The ALLP and MLLP were obtained at $320^{\circ} \mathrm{C}, 30 \mathrm{~min}$.

The total phenol content (per 100g) of ALLP increased greatly after liquefaction, and it nearly doubled that of alkaline lignin. In contrast, the total phenol content increased relatively little (by only 9.5\%) after the liquefaction of magnesium lignosulfonate, as shown in Fig. 5. Compared with the liquefaction products, the alkaline lignin and magnesium lignosulfonate were found to contain a small quantity of water, water-soluble salt, cellulose, and xylan. Water and water-soluble salts were removed or reduced in the liquefaction products. Also, the gasification ratios of cellulose and xylan were much higher than lignin at high temperature (Yoshida et al. 2001, 2004; Izumizaki et al. 2005). Much more cellulose and xylan were converted to gas at higher temperature, and the liquefaction products of cellulose and xylan in ALLP and MLLP may be relatively low. So liquefaction of alkaline lignin is conducive to the increase of phenol content. The mechanism that may account for the relatively low increase of phenol content in MLLP after magnesium lignosulfonate liquefaction is not clear; though one possible reason is 
that more phenolic compounds in MLLP result in char formation due to the condensation in the absence of alkali.

Table 1. Phenolic Compounds Detected by GC/MS Analysis as in Fig. 4.

\begin{tabular}{|c|c|c|c|c|c|c|c|c|}
\hline No. & $\begin{array}{l}\text { Chemical } \\
\text { structure }\end{array}$ & $\begin{array}{l}\% \\
\text { Similarity }\end{array}$ & No. & $\begin{array}{l}\text { Chemical } \\
\text { structure }\end{array}$ & $\begin{array}{l}\% \\
\text { Similarity }\end{array}$ & No. & $\begin{array}{l}\text { Chemical } \\
\text { structure }\end{array}$ & $\begin{array}{l}\% \\
\text { Similarity }\end{array}$ \\
\hline 1 & & 96 & 11 & & 88 & 21 & & 89 \\
\hline 2 & & 92 & 12 & & 96 & 22 & & 90 \\
\hline 3 & & 92 & 13 & & 92 & 23 & & 93 \\
\hline 4 & & 89 & 14 & & 90 & 24 & & 82 \\
\hline 5 & & 92 & 15 & & 82 & 25 & & 86 \\
\hline 6 & & 97 & 16 & & 96 & 26 & & 94 \\
\hline 7 & & 85 & 17 & & 90 & 27 & & 84 \\
\hline 8 & & 87 & 18 & & 90 & 28 & & 80 \\
\hline 9 & & 92 & 19 & & 90 & 29 & & 96 \\
\hline 10 & & 91 & 20 & & 92 & 30 & & 78 \\
\hline
\end{tabular}



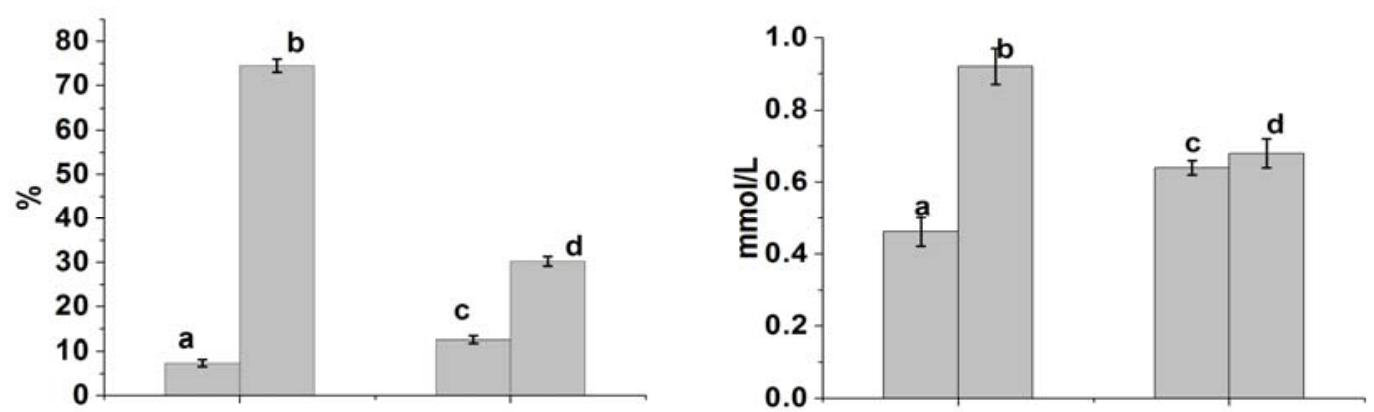

Fig. 6. (left). DPPH radicals scavenging percentages; the test condition was that $0.2 \mathrm{~mL}$ samples were mixed with $5 \mathrm{~mL} 5 \times 10^{-5} \mathrm{~mol} / \mathrm{L}$ DPPH radical ethanol solutions. a: alkaline lignin; $\mathbf{b}$ : ALLP; : magnesium lignosulfonate; and d: MLLP. The ALLP and MLLP were obtained at $320^{\circ} \mathrm{C}, 30 \mathrm{~min}$.

Fig. 7. (right). The detected concentrations of $\mathrm{Fe}^{2+}$ by FRAP method. $\mathbf{a}$ : alkaline lignin; b: ALLP; c: magnesium lignosulfonate; and $\mathbf{d}$ : MLLP. The ALLP and MLLP were obtained at $320{ }^{\circ} \mathrm{C}$, 30min.

In Fig. 6, compared with alkaline lignin, the DPPH radicals scavenging percentage was increased from $7.3 \%$ to $74.5 \%$ by ALLP; and compared with magnesium lingosulfonate, the DPPH radicals scavenging percentage was increased from $12.6 \%$ to $30.2 \%$ by MLLP. In Fig. 7, the higher concentration of $\mathrm{Fe}^{2+}$ implies stronger the reducing power. Compared with alkaline lignin, the concentrations of $\mathrm{Fe}^{2+}$ with ALLP addition by FRAP method was nearly doubled, while compared with magnesium lignosulfonate, the concentrations of $\mathrm{Fe}^{2+}$ with MLLP addition increased only a little. The reasons for increase of antioxidant power after liquefaction can be explained as due to the higher phenol content, lower molecular weights, and better mobility. Comparing Fig. 5 with Fig. 6 , the change degree of the DPPH radicals inhibition was more sensitive than that of $\mathrm{Fe}^{2+}$ concentration, which indicates the enhancement in the ability to capture radicals is stronger than that of reduction capacity after liquefaction. Also the results confirm that phenolic compounds as antioxidants mainly depend on their abilities to capture free radicals. Also, the results from Fig. 5-7 demonstrated that ALLP has higher increased antioxidant power than MLLP. So alkaline lignin and DPPH method were selected to test the influence of reaction time and temperature.

The effects of temperature and reaction time on oil yield, total phenol content, and DPPH radicals scavenging percentages of ALLP are shown in Figs. 8 and 9, respectively. The oil yield at $320{ }^{\circ} \mathrm{C}, 30 \mathrm{~min}$ achieved a maximum value, suggesting that a longer residence time and higher temperature are not necessary for a higher yield of the oil production. Two possible reasons to account for the level-off of the oil yields at a prolonged reaction time and elevated temperature would be: (a) cracking of the liquid products to gases and (b) formation of char by condensation, cyclization, and repolymerization of the liquid products (Xu and Etcheverry 2008; Tymchyshyn and $\mathrm{Xu}$ 2010). From Figs. 8 and 9, the total phenol content increased from 280 to $300^{\circ} \mathrm{C}$, and then decreased with further increase of temperature from 300 to $350^{\circ} \mathrm{C}$ at a reaction time of 30 min, while the total phenol content decreased markedly with increased reaction time at $320{ }^{\circ} \mathrm{C}$. The results are likely due to that the decomposition degree of alkaline lignin to 
phenolic compounds was not high enough at relative low temperature $\left(280^{\circ} \mathrm{C}\right)$, and the longer reaction time and elevated temperature are attributed to the enhanced condensation reactions of the phenolic products to form char, which results in low total phenol content in ALLP. Tymchyshyn and Xu (2010) have found the char formed by phenolic/neutral oils increased with increasing temperature by hydrothermal liquefaction of lignin within the range 250 to $350{ }^{\circ} \mathrm{C}$.

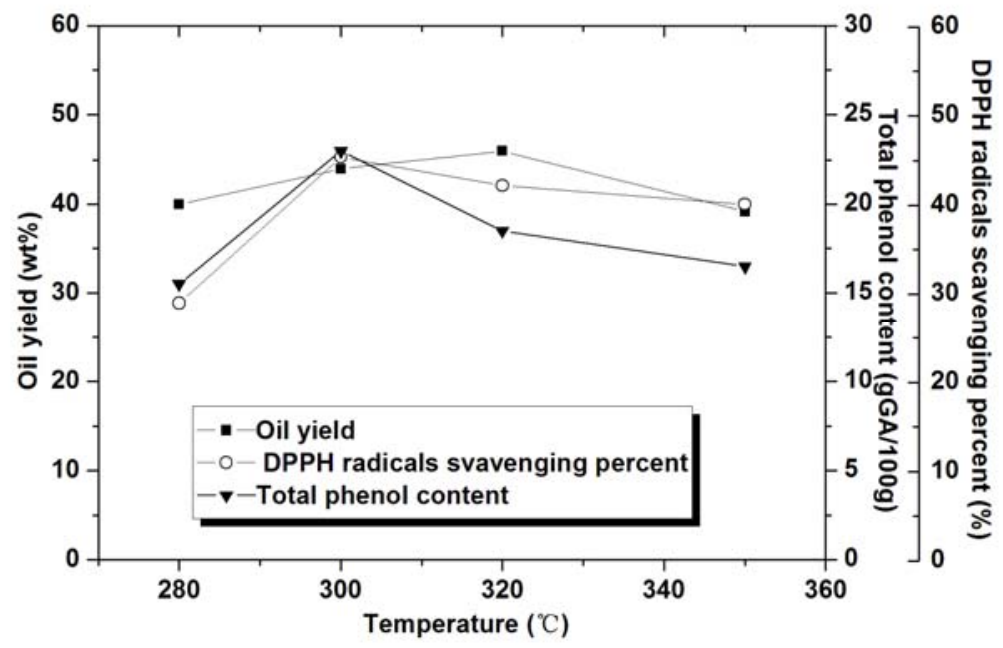

Fig. 8. Oil yield, total phenol content, and DPPH radicals scavenging percentages of ALLP at various temperatures at $30 \mathrm{~min}$. In the DPPH method test condition $0.2 \mathrm{~mL}$ samples were mixed with $6 \mathrm{~mL} 1 \times 10^{-4} \mathrm{~mol} / \mathrm{L}$ DPPH radicals ethanol solutions.

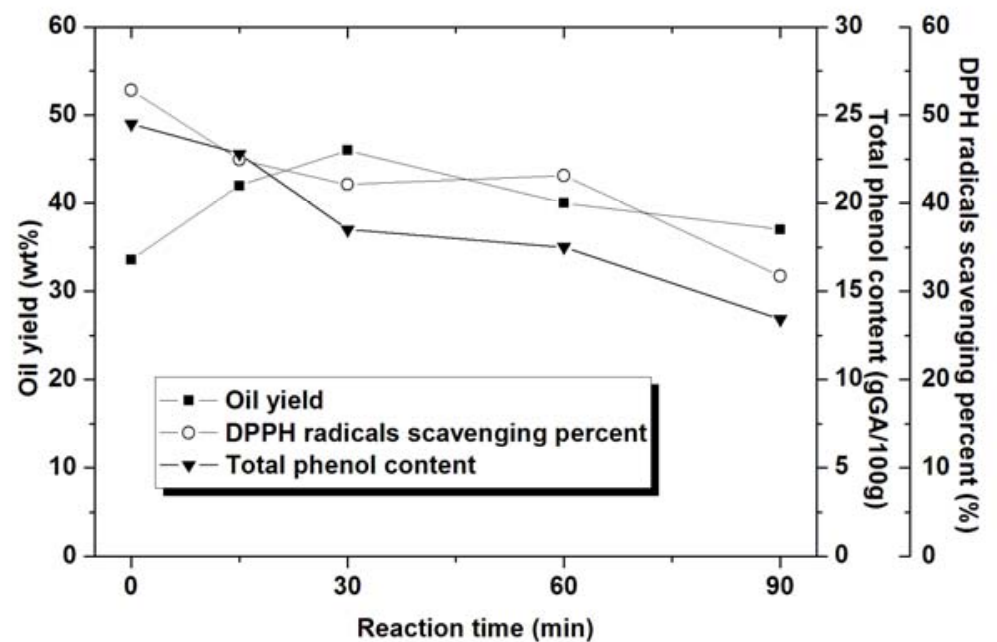

Fig. 9. Oil yield, total phenol content, and DPPH radicals scavenging percentages of ALLP at various reaction time at $320{ }^{\circ} \mathrm{C}$. In the DPPH method test condition $0.2 \mathrm{~mL}$ samples were mixed with $6 \mathrm{ml} 1 \times 10^{-4} \mathrm{~mol} / \mathrm{L}$ DPPH radicals ethanol solutions. 
The change trends of DPPH radicals scavenging percentages with reaction time and temperature were similar to that of the total phenol content. Considering the oil yield, total phenol content and antioxidant ability, the process parameters at $300{ }^{\circ} \mathrm{C}, 30 \mathrm{~min}$ or $320^{\circ} \mathrm{C}, 15 \mathrm{~min}$ are suitable conditions for antioxidant ALLP production. For all these values in Fig. 8 and 9, there is certain correlation between total phenol content and DPPH radicals scavenging percentages (linear correlation $\mathrm{R}^{2}=0.7756$ ). However, it is difficult to explore the specific mechanism of the antioxidant power with the ALLP: (1). There are some low molecular carbohydrates in the liquid products, the aliphatic hydroxyl groups in these carbohydrates can decrease antioxidant activity since their polar groups may hydrogen bond with phenolic groups (Ugartondo et al. 2008). (2). In the ALLP, there may be some other antioxidant compounds, such as flavonoids. (3). There are various molecular weights and great diversity phenols in the ALLP. It has been reported that phenolic interactions can positively or negatively affect the antioxidant activity of natural mixtures (Iacopini et al. 2008).

Compared with the lignins, the hydrothermal liquefaction products greatly improved the unit antioxidant power. Due to this ability, together with their liquid nature, these liquefaction products may have the potential to serve a broader range of applications and achieve advantages in many liquid systems, such as in bio-diesel and lubricants, where phenolic antioxidants are often added.

\section{CONCLUSIONS}

Hydrothermal liquefaction products retained the basic functional groups of lignins. Compared with the raw materials, both ALLP and MLLP improved the unit antioxidant power, while ALLP showed better antioxidant abilities as measured by the DPPH method and FRAP method. The total phenol content had certain relationships with the antioxidant abilities. ALLP have the potential to become used as liquid antioxidants, suitable conditions for alkaline lignin hydrothermal liquefaction are at $300{ }^{\circ} \mathrm{C}, 30 \mathrm{~min}$ or $320{ }^{\circ} \mathrm{C}, 15 \mathrm{~min}$.

\section{ACKNOWLEDGMENTS}

The authors would like to acknowledge financial support from the National Basic Research Program of China (973 Program) (No. 2010CB732205).

\section{REFERENCES CITED}

Bhat, R., Khalil, H. P. S. A., and Karim, A. A. (2009). "Exploring the antioxidant potential of lignin isolated from black liquor of oil palm waste," C.R. Biol. 32, 827831. 
Brand-Williams, W., Cuvelier, M. E., and Berset, C. (1995). "Use of a free radical method to evaluate antioxidant activity," Lebensm.-Wiss. u.-Technol. 28, 25-30.

Castro, E., Conde, E., Cara, C., Moure, A., Falqué, E., Cara, C., Ruiz, E., and Domínguez, H. (2008). "Antioxidant activity of liquors from steam explosion of Olea europea wood," Wood Sci. Technol.42, 579-592.

Dobele, G., Dizhbite, T., Urbanovich, I., Andersone, A., Ponomarenko, J., and Telysheva, G. (2009). "Pyrolytic oil on the basis of wood and the antioxidant properties of its water soluble and -insoluble fraction," J. Anal. Appl. Pyrolysis 85, 81-86.

Iacopini, P., Baldi, M., Storchi, P., Sebastiani, L. (2008). “Catechin, epicatechin, quercetin, rutin and resveratrol in red grape: Content, in vitro antioxidant activity an interactions," J. Food Compos. Anal. 21,589-598.

Izumizaki, Y., Park, K., Tachibana, Y., Tomiyasu, H., and Fujii, Y. (2005). “Organic decomposition in supercritical water by an aid of ruthenium(IV) oxides as a catalyst exploitation of biomass resources for hydrogen production," Prog. Nucl. Energ. 47, 544-522.

Osada, M. Sato, T. Watanabe, Shirai, M., and Arai, K. (2006). "Catalytic gasification of woodbiomass in subcritical and supercritical water," Combust. Sci. Technol. 178, 537-552.

Pan, X., Kadla, J. F., Ehara, K., Gilkes, N., and Saddler, J. N. (2006). “Organosolv ethanol lignin from hybrid poplar as a radical scavenger: Relationship between lignin structure, extraction conditions, and antioxidant activity," J. Agric. Food. Chem. 54, 5806-5813.

Ugartondo, V. Mitjans, M., and Vinardell, M. P. (2008). "Comparative antioxidant and cytotoxic effects of lignins from different sources," Bioresour. Technol. 99, 66836687.

Watanabe, M., Inomata, H., Osada, M., Sato, T., Adschiri, T., and Arai, K. (2003). "Catalytic effects of $\mathrm{NaOH}$ and $\mathrm{ZrO}_{2}$ for partial oxidative gasification of nhexadecane and lignin in supercritical water," Fuel 82, 545-552.

Xin, J., and Saka, S. (2009). "Improvement of the oxidation stability of biodiesel as prepared by supercritical methanol method with lignin," Eur. J. Lipid Sci. Technol. $111,835-842$.

$\mathrm{Xu}, \mathrm{C}$., and Etcheverry, T. (2008). "Hydro-liquefaction of woody biomass in sub- and super-critical ethanol with iron-based catalysts," Fuel 87, 335-345.

Tymchyshyn, M., Xu, C. (2010). "Liquefaction of bio-mass in hot-compressed water for the production of phenolic compounds," Bioresour. Technol. 101, 2483-2490

Yoshida, T., and Matsumura, Y. (2001). "Gasification of cellulose, xylan, and lignin mixtures in supercritical water,” Ind. Eng. Chem. Res. 40, 5469-5474.

Yoshida, T., Oshima, Y., and Matsumura, Y. (2004). "Gasification of biomass model compounds and real biomass in supercritical water," Biomass Bioenerg. 26, 71-78.

Article submitted: October 30, 2010; Peer review completed: November 20, 2010;

Revised version received and accepted: December 2, 2010; Published: December 3, 2010. 